University of Nebraska - Lincoln

DigitalCommons@University of Nebraska - Lincoln

Faculty Publications of the Center on Children, Families, and the Law

Children, Families, and the Law, Center on

2007

Development and Confirmatory Factor Analysis of the Community Norms of Child Neglect Scale

\author{
Rebecca Goodvin \\ David R. Johnson \\ Sam A. Hardy \\ Michelle Graef \\ Jeff M. Chambers
}

Follow this and additional works at: https://digitalcommons.unl.edu/ccflfacpub

Part of the Administrative Law Commons, Courts Commons, Criminology and Criminal Justice Commons, Domestic and Intimate Partner Violence Commons, Family Law Commons, Family, Life Course, and Society Commons, Juvenile Law Commons, Law and Psychology Commons, Law Enforcement and Corrections Commons, Nonprofit Organizations Law Commons, Social Policy Commons, Social Welfare Commons, and the Social Welfare Law Commons

This Article is brought to you for free and open access by the Children, Families, and the Law, Center on at DigitalCommons@University of Nebraska - Lincoln. It has been accepted for inclusion in Faculty Publications of the Center on Children, Families, and the Law by an authorized administrator of DigitalCommons@University of Nebraska - Lincoln. 


\title{
Development and Confirmatory Factor Analysis of the Community Norms of Child Neglect Scale
}

Rebecca Goodvin, University of Nebraska-Lincoln; Center on Children, Families, and the Law

David R. Johnson, Pennsylvania State University

Sam A. Hardy, University of Virginia

Michelle I. Graef \& Jeff M. Chambers, University of Nebraska-

Lincoln; Center on Children, Families, and the Law

\begin{abstract}
This article describes the development of the Community Norms of Child Neglect Scale (CNCNS), a new measure of perceptions of child neglect, for use in community samples. The CNCNS differentiates among four subtypes of neglect (failure to provide for basic needs, lack of supervision, emotional neglect, and educational neglect). Scenarios ranging in seriousness for each subtype were presented to a large community sample $(\mathrm{N}=3,809)$. Confirmatory factor analyses indicated that a fourfactor model provided a better fit to the data than did a model specifying only one overall neglect factor, suggesting this sample distinguished among the four subtypes of neglect. The authors tested measurement equivalence across individuals who work with children and lay community respondents and across rural and urban respondents, with results indicating a very similar structure across these groups. These initial reliability and validity data suggest that the CNCNS may be of use in comparing perceptions of child neglect among individuals and across communities.
\end{abstract}

Keywords: child neglect, norms, perceptions, measure, rural-urban, sentinel

Published in Child Maltreatment, Vol. 12, No. 1, February 2007 68-85

DOI: $10.1177 / 1077559506296667$

Copyright (C) 2007 Sage Publications. Used by permission.

PMID: 17218649

This study was supported by Grant Ro1 HD42241, “The Community Context of Rural and

Urban Child Neglect," from National Institute of Child Health and Human Development. 
Child neglect has the highest incidence rate of all types of maltreatment in the United States; in 2004, nearly 550,000 children were neglected (U.S. Department of Health and Human Services, Administration on Children, Youth and Families, 2006). To better address the problem of child neglect, researchers must endeavor to learn more about child neglect at all levels, from individual developmental sequelae of neglect to the broader contextual factors implicated in the incidence of and response to this problem. Individuals' perceptions of neglect have received comparatively little attention, despite the fact that individual community members' perception that child neglect may be occurring is a first step toward addressing the situation, whether by informal direct contact with the family or by reporting their observations to authorities. At present, however, we do not have an adequate understanding of perceptions of child neglect in broad community samples. This article describes the development and validation of the Community Norms of Child Neglect Scale (CNCNS), a brief survey assessing individuals' perceptions of potentially neglectful behaviors. In addition, we tested the CNCNS for measurement equivalence across individuals who work in a professional capacity with children (i.e., sentinels) and lay community members and across rural and urban residents.

Several studies examining community member and child welfare workers' perceptions of child maltreatment exist; most have encompassed perceptions of multiple types of child maltreatment (i.e., physical abuse, sexual abuse, and neglect) rather than focusing specifically on neglect (e.g., Bensley et al., 2004; Hong \& Hong, 1991; Portwood, 1998; Price et al., 2001; Roscoe, 1990; Shor, 2000). This general approach seems to have largely precluded a more sophisticated understanding of the variability of perceptions of different types of child neglect. Most studies focusing specifically on perceptions of neglect have either not split neglect into subtypes (e.g., Craft \& Staudt, 1991), have used exploratory factor analysis to derive post hoc subtypes (e.g., Rose \& Meezan, 1995), or have examined many specific subtypes, diminishing the feasibility of using the scale for any purpose beyond descriptive analyses (e.g., Rose, 1999; Rose \& Meezan, 1996).

In these studies, and those designed for clinical purposes of assessing experiences of neglect (e.g., Harrington, Zuravin, DePanfilis, Ting, \& Dubowitz, 2002; Strauss, Kinard, \& Williams, 1995; Trocmé, 1996), researchers have proposed a number of subclassification systems for 
different types of neglect (see Zuravin, 1999). We developed the present measure based on a classification approach suggested by Barnett, Manly, and Cicchetti (1993), selected because of its relative parsimony and because of its careful construction based on theoretical literature on child maltreatment, consultation with other child maltreatment experts, and child protective services (CPS) records. Barnett and colleagues identified four broad subtypes of child neglect that represent a range of observed incidents in CPS case files: physical neglect- failure to provide, physical neglect-lack of supervision, emotional maltreatment, and moral, legal, or educational maltreatment. This classification system appears to capture a majority of the more specific subtypes of neglect identified in other research. For example, physical neglect-failure to provide would appropriately encompass inadequate food, clothing, shelter, and medical care. In addition, this model is consistent with a conceptualization of neglect linked to children's basic needs, and Barnett et al. give examples on a continuum of severity based on potential for negative developmental impact. Using this model as a foundation, goals of the present study were to examine individual community participants' perceptions of what constitutes child neglect and to test whether community participants distinguish between multiple subtypes of neglect, or if one overarching neglect factor is adequate to account for community members' perceptions of child neglect situations.

\section{Community Subgroups: Sentinel Group Status and Rural-Urban Residence}

From an ecological perspective (e.g., Belsky, 1980, 1993), it is also necessary to recognize that cultural and contextual factors contribute to individuals' perceptions of children's needs and of appropriate treatment of children. Thus, we sought to examine perceptions of neglect across groups of individuals who may hold different normative beliefs regarding what constitutes child neglect and to assess the equivalence of identified neglect subtypes across these groups. Based on previous research, two distinctions that we deemed particularly relevant to examine in this study were sentinels versus nonsentinels and rural versus urban residents. Sentinels, or individuals who work in a professional capacity with children, are one group whose views of child neglect might diverge from the general population because of their 
more frequent exposure to a broader sample of children and families and perhaps more extensive knowledge of child development. Earlier studies have indicated that child maltreatment professionals perceive hypothetical neglect scenarios as being less serious in general than do lay community members (e.g., Dubowitz, Klockner, Starr, \& Black, 1998; Rose, 1999; Rose \& Meezan, 1995, 1996), suggesting that professionals' unique perspectives may foster a higher threshold for considering the seriousness of child neglect scenarios.

Previous studies have derived subtypes of neglect across professional and nonprofessional groups using factor analysis (e.g., Dubowitz et al., 1998; Rose \& Meezan, 1995). However, none of these studies has tested the adequacy of the structural fit of the factors across the subgroups examined. Studies noted above suggest mean differences in lay community members' and child welfare workers' perceptions of the seriousness of specific neglect scenarios and factors. However, these studies do not test the possibility that the same scales may not be comparable for these two groups, given their differing levels of exposure to and experience with a range of child neglect situations. To determine the comparability of neglect classifications across these two populations, measurement comparisons across child welfare sentinels and nonsentinel community members are necessary.

The second population subgrouping of interest in this study was rural-urban residence. Residents of rural and urban communities differ on a number of values and attitudes that potentially affect their social perceptions and behaviors (Wagenfeld \& Wagenfeld, 1981), including those pertaining to parenting and child neglect. These differences include the tendency for rural residents to be more self-reliant and socially and politically more conservative and to hold stronger work ethics and more fatalistic views than urban residents (Flax, Wagenfeld, Ivens, \& Weiss, 1979; Wilkinson, 1991). Rural areas are also characterized by lower rates of use of formal social and health services compared to urban areas, and rural residents are often more suspicious of and concerned about the appropriateness of these services (Wagenfeld \& Wagenfeld, 1981). Variation in the economic and social characteristics and values of rural and urban communities may shape what types of parenting behaviors people in those communities perceive to constitute child neglect or the seriousness that they ascribe to those situations (e.g., Heller, Queseda, Harvey, \& Warner, 1981; Lichter \& Eggebeen, 1992). In comparison to urban areas, lower paid work and 
lower employment rates are characteristic of rural economies (e.g., Brown \& Hirshl, 1995), raising the possibility that normative perceptions of physical resources vary by rural-urban ecology. In addition, social networks are likely to be larger and more diverse in rural communities (Fischer, 1982), and as a result, social network surveillance of children may be more common in rural than in urban areas. Studies have found that rural residents are more likely than urban residents to extend help to strangers and persons who are not friends or relatives (Amato, 1993; Steblay, 1987). In this way, the perception in rural communities that others are "keeping an eye out" may lead to different expectations about parental supervision of children than those held by urban residents. Despite these potential differences, only one study to date has examined perceptions of child neglect across rural and urban communities. Craft and Staudt (1991) asked rural and urban community members to rate hypothetical neglect scenarios for the likelihood that they or someone else in their town would report the situation. These researchers found little difference between rural and urban participants, although this may have been a methodological artifact resulting from the researchers' giving participants a definition of neglect at the beginning of the interviews. In short, we know very little about how perceptions of neglect might vary across ruralurban ecology and nothing about whether rural and urban community members distinguish subtypes of neglect in similar ways.

\section{Current Study}

The primary goals of the current study were to develop a brief measure of perceptions of child neglect that would be appropriate for use across a wide range of samples, to examine perceptions of what constitutes child neglect in a large community sample, and to test in a community sample support for a model distinguishing among neglect subtypes. Based in an ecological perspective, a second aim was to examine and, if possible, establish measurement equivalence across child welfare sentinels and nonsentinels and across individuals in rural and urban communities. In addition to testing equivalence of scales across these groups, we explore potential differences in norms of neglect between sentinels and nonsentinels and between rural and urban individuals. Ultimately, our goal was to develop a measure that would be appropriate for future research aimed at further understanding child 
neglect rates and reporting and possible individual- and/or community-level differences in perceptions of neglect norms.

\section{Development of the CNCNS}

We conceptualized neglect as situations that are largely indicative of caregivers' failure to meet children's needs and are implicated in risk for negative developmental outcomes (see Dubowitz et al., 2005; Manly, Cicchetti, \& Barnett, 1994). Barnett and colleagues' (1993) typology of child neglect provided an attractive foundation for the development of a new scale of neglect perceptions because of its focus on a limited number of distinct neglect subtypes derived from actual CPS incidents and ranging in severity of potential impact on children's development. We initially used Barnett et al.'s definitions and examples to generate a pool of 20 items representing physical neglect (failure to provide and lack of supervision), emotional maltreatment, and educational maltreatment. We considered each of these scenarios to represent child neglect within Barnett et al.'s system. We wrote 14 additional scenarios based on Barnett et al.'s definitions and on the presence of potential for harm to the child; we added these scenarios to incorporate low-severity items and items that we thought might show variability between communities or groups of participants. Although all of these scenarios present a situation with some risk of negative impact to the child's development, it is possible that not all would be classified as child neglect using Barnett et al.'s system (or using legal standards for neglect). We intended scenarios to elicit a range of severity ratings, but we were especially interested in items with ambiguity regarding their status as neglect. In other words, we included a relatively larger number of scenarios that we considered low severity within Barnett et al.'s system, with the goal of discerning variation in perceptions of what constitutes neglect. As a result, we did not include scenarios on which we would expect near unanimous agreement of "severe neglect" among community members, as we anticipated little variation in severity ratings in this type of scenario. The CNCNS items thus reflect a more narrow range of behaviors and situations than might be found in a more comprehensive taxonomy of neglect.

A sample of 229 undergraduate and graduate students, 18 to 31 years old (62.0\% female; $84.7 \%$ White) from both rural and urban 
areas at two midwestern universities completed a 34-item measure. For each item, participants indicated whether they believed the scenario indicated child neglect and, if so, the seriousness of the situation (5-point scale). Based on exploratory factor analysis and scale analysis of the pilot data, items were selected for the final scale if they (a) had an acceptable loading ( $>.4$ ) on the intended factor, (b) demonstrated variability in the proportion of respondents identifying the item as neglect, and (c) displayed variability in the rating of the seriousness of the neglect. A total of 21 items, representing four subtypes of neglect, composed the scale used in the current study.

\section{Method}

\section{Procedure}

As part of a larger study of community differences in the incidence, identification, and reporting of child neglect, the CNCNS was included in a telephone survey of community residents and sentinels in $50 \mathrm{com}-$ munities in a midwestern state. Communities, selected to include a range of rural and urban areas, were defined by zip code in the nonmetropolitan areas and by census tract in the metropolitan areas. We considered communities within a county in a metropolitan statistical area (MSA) to be urban and those outside an MSA to be rural. The U.S. Census Bureau defines an MSA as a core urban area of at least 50,000, together with surrounding communities having a high degree of economic and social integration with the core. In smaller, rural communities, zip code areas correspond closely to the political boundaries of the communities and are the best available community boundary for which aggregate community-level data can be generated (Osgood \& Chambers, 2000). Census tracts are preferred to zip code areas in urban areas, as they generally follow social and economic boundaries and normally correspond more closely than zip codes to socially defined neighborhoods within the larger cities (see Coulton, Korbin, Su, \& Chow, 1995; Zuravin \& Taylor, 1987).

We selected the sample of communities in two stages. In the first stage, we sampled CPS office areas using a stratified random procedure from among the 43 in the state. The CPS office areas were divided into three strata: offices covering metropolitan areas $(n=3)$, 
offices covering both rural and urban areas $(n=2)$, and offices covering rural areas $(n=4)$. In the second stage, we selected zip code or census tract areas within the 10 CPS office areas using a disproportionate stratified sampling design. Within each office area, census data were used to create three population density/community size strata, and within each of these, two income strata. We used an equal probability of selection model to draw two to three zip code or census tract areas in each stratum. This design resulted in oversampling of rural, more ethnically diverse, and lower income communities.

Within the 50 sampled areas, both random-digit dialing and listed samples of telephone numbers within the zip code and census tract areas were purchased and used to contact the sample. A screener item was included on the survey to ascertain if the respondent fell within the boundaries of the study areas; those outside the boundaries were excluded. We supplemented this sample in many of the communities with additional names and telephone numbers of persons identified as most knowledgeable about the treatment of children in the community (i.e., sentinels). The respondent in the sampled households was selected at random from among all persons age 19 and older residing in the household. There were approximately 75 respondents per community, resulting in completed interviews for 3,826 respondents. The response rate was 59\% (American Association for Public Opinion Research [AAPOR] response rate 2 ), and the cooperation rate was $70 \%$ (AAPOR cooperation rate 2 ).

\section{Measures}

The CNCNS consists of 21 brief scenarios; respondents rated severity of each scenario on a 6 -point scale ( $\mathrm{o}=$ not neglect, $5=$ very serious ne-

glect). These scenarios represent different aspects of four subtypes of child neglect, operationalized based on Barnett et al.'s (1993) maltreatment classification system. Emotional neglect was defined as a failure to respond to children's basic emotional needs, including safety and security, acceptance and self-esteem, and age-appropriate autonomy. Physical neglect-failure to provide was defined as a failure to meet children's physical needs, including food, hygiene, clean and appropriate clothing, adequate shelter, and health care. Physical neglect-lack of supervision was defined as failure to ensure the child's safety, including not ensuring that the child is engaged in safe activities, not ensuring a safe 
environment, and not ensuring safe substitute care. Educational neglect was defined as failure to ensure that the child is regularly attending school and to attend to the child's success in school.

In addition to the CNCNS, participants responded to demographic questions regarding their gender, age, and educational attainment, the number of children in their household, and their annual household income. Participants also answered questions about their observations of children and completed several measures of community context and values not reported in this study.

\section{Sample Characteristics}

The sample for the present study included 3,809 adults. Of the original sample of 3,826 , a small number $(n=17)$ were omitted because of lack of information to identify their sentinel status, leaving 407 sentinels and 3,402 nonsentinels. Participants were socioeconomically heterogeneous but, reflective of the state in which this study was conducted, represent little racial or ethnic diversity. Total sample demographics are comparable to state population demographics, with the exception of rural residence, as our design intentionally oversampled rural areas and small communities. We report demographic characteristics for the full sample, the state population, and subgroups in Table 1.

Table 1. Demographic Statistics for the State Population, Full Sample, and Subgroups

\begin{tabular}{lcccccc} 
Variable & State & Full Sample & Sentinel & Nonsentinel & Rural & Urban \\
\hline M age (SD) & NA & $51.21(17.05)$ & $51.96(17.43)$ & $45.14(11.93)$ & $51.03(17.54)$ & $51.91(14.99)$ \\
Median age & 35.8 & 50.0 & 46.0 & 50.0 & 51.0 & 44.0 \\
\% female & 50.7 & 59.9 & 81.0 & 57.0 & 60.0 & 58.0 \\
\% White & 89.6 & 96.7 & 95.2 & 96.8 & 98.0 & 94.4 \\
M years school (SD) & NA & $13.65(2.58)$ & $15.86(2.67)$ & $13.38(2.44)$ & $13.59(2.57)$ & $13.91(2.62)$ \\
\% college degree & 24.8 & 23.4 & 61.2 & 20.1 & 20.5 & 40.8 \\
\% below poverty & 9.7 & 9.5 & 4.0 & 10.1 & 10.7 & 4.6 \\
M number in household & 2.48 & $2.44(1.33)$ & $2.78(1.42)$ & $2.40(1.31)$ & $2.34(1.35)$ & $2.83(1.19)$ \\
Median household income & $\$ 39,904$ & $\$ 30,000-$ & $\$ 30,000-$ & $\$ 30,000-$ & $\$ 30,000-$ & $\$ 30,000-$ \\
& & $\$ 39,000$ & $\$ 39,000$ & $\$ 39,000$ & $\$ 39,000$ & $\$ 39,000$ \\
\% sentinel & $\mathrm{NA}$ & 10.7 & - & - & 11.3 & 9.8 \\
\% rural & 45.0 & 79.7 & 81.9 & 79.4 & - & - \\
\hline
\end{tabular}

Source: State data are from the 2002 U.S. Census. NA = not available. 
Sentinels were identified using occupational categories from the Third National Incidence Study of Child Abuse and Neglect (NIS; Sedlak \& Broadhurst, 1996). The NIS has identified professional occupations in which individuals are likely to encounter maltreated children during the course of their normal job duties. NIS sentinel occupations represented in the present study include medical professions (38.3\%; e.g., doctors, nurses), mental health professions (2.7\%; e.g., counselor, therapist), law enforcement (2.7\%; e.g., police, sheriff), education personnel (47.5\%; e.g., teacher, school counselor), and child care providers (8.8\%; e.g., in-home day care provider, center direct care staff). Although both sentinels (95\%) and nonsentinels (86\%) reported having observed at least one child in the past year, sentinels (58\%) were more likely than nonsentinels (10\%) to work professionally with children. For each of the four subtypes of neglect, the proportion of sentinels reporting that they had observed at least one child experiencing that type of neglect during the past year was nearly twice that of nonsentinels ( $M=58 \%$ of sentinels vs. $28 \%$ of nonsentinels).

\section{Data Analysis Plan}

The first step in data analysis was to examine the internal consistency (using Cronbach's $\alpha$ coefficients) of the full scale and the four subscales for the combined sample. The second step employed confirmatory factor analysis (CFA) to test whether the four conceptually defined subscales were an adequate fit to the pattern of observed item relationships in the full sample. We also tested multiple-group models to assess differences in the factor structure fit between sentinels and nonsentinels and between respondents in rural and urban areas.

Although the amount of missing data on the scale items was very low $(2.2 \%)$, to retain the maximum number of respondents in the study, the missing values were handled in one of two ways. For the descriptive tables and reliability estimates, the missing values were imputed using the EM method in the SPSS MVA module (Hill, 1997). For the confirmatory analysis, conducted in Mplus (Muthen \& Muthen, 2004), we used the full information maximum likelihood method so that cases with both complete and incomplete data would be included in the confirmatory factor models. A comparison of the results including and excluding cases with missing observations revealed no substantively meaningful differences. 


\section{Results}

\section{Internal Consistency Reliability}

In the total sample, internal consistency for all 21 items was high ( $\alpha=.94$ ) and was moderately high for the Emotional Neglect ( $\alpha=.82$ ), Lack of Supervision $(\alpha=.84)$, Failure to Provide $(\alpha=.84)$, and Educational Neglect ( $\alpha=.85$ ) subscales. Following item analysis, we identified items that did not fit well on their specified subscale. The Emotional Neglect and Lack of Supervision subscales each contained one item that, if removed, would lead to an improvement in internal reliability (based on the alpha-if-item-deleted values). These two items ("A parent leaves their child with a relative for two weeks with no indication of when or if she is returning" and "A six-year-old gets in trouble with neighbors because his parents were not supervising him") were dropped from the scales and excluded from further analyses. Final items and descriptive statistics for the overall sample, by sentinel group and by rural-urban residence, are presented in the appendix. In addition, in the appendix we identify the percentage of respondents who indicated that each scenario was not neglectful.

\section{CFAs}

A series of CFAs was performed in the full sample to determine model structure among the 19 remaining items. Our first goal was to assess whether a single overall factor adequately accounted for the pattern of covariances among the items. If this more parsimonious model did not fit the data, our second goal was to test the classification of items into four types of neglect. If the four-factor model demonstrated a reasonable fit, then a third goal was to test a hierarchical factor structure. This third model would test whether a single second-order factor (Overall Neglect) accounts for relations among the four latent factors. The CFA models were estimated in Mplus (Muthen \& Muthen, 2004). To assess model fit, we used the root mean square error of approximation (RMSEA) and fit statistics based on Hu and Bentler's (1999) combinatorial rule. This rule asserts that a standardized root mean square residual (SRMR) of $\leq .08$ and a comparative fit index (CFI) of $\geq .95$ demonstrate adequate fit. We used a chi-square test to evaluate the difference in fit between nested models (see Table $\mathbf{2}$ for fit 
Table 2. Fit Indices for Confirmatory Factor Analysis in Full Sample and by Group

\begin{tabular}{|c|c|c|c|c|c|c|c|}
\hline Model & SRMR & CFI & RMSEA & $\chi^{2}$ & $d f$ & $\Delta \chi^{2}$ & $\Delta d f$ \\
\hline \multicolumn{8}{|l|}{ Full sample } \\
\hline 1. 1 factor & .038 & .916 & .069 & 2909.65 & 152 & & \\
\hline 2. 4 factors & .023 & .974 & .040 & 1008.54 & 145 & & \\
\hline 3. $4+1$ factors & .023 & .974 & .039 & 1019.11 & 147 & & \\
\hline \multicolumn{8}{|l|}{ Sentinel and nonsentinel groups } \\
\hline 4. $4+1$ factors, $\lambda$ constrained & .030 & .971 & .039 & 1298.26 & 326 & & \\
\hline 5. $4+1$ factors, $\lambda$ unconstrained & .026 & .971 & .040 & 1271.04 & 311 & $27.22^{*}$ & 15 \\
\hline $\begin{array}{l}\text { 6. } 4+1 \text { factors, } \lambda \text { for } 3 \text { items unconstrained }{ }^{a} \\
\text { others constrained }\end{array}$ & .027 & .971 & .039 & 1279.85 & 323 & $18.41^{*}$ & 3 \\
\hline \multicolumn{8}{|l|}{ Rural and urban groups } \\
\hline 7. $4+1$ factors, $\lambda$ constrained & .032 & .970 & .040 & 1522.61 & 326 & & \\
\hline 8. $4+1$ factors, $\lambda$ unconstrained & .027 & .966 & .045 & 1489.12 & 311 & $33.49^{*}$ & 15 \\
\hline $\begin{array}{l}\text { 9. } 4+1 \text { factors, } \lambda \text { for } 4 \text { items unconstrained, }{ }^{\text {b }} \\
\text { others constrained }\end{array}$ & .028 & .966 & .044 & 1496.11 & 322 & $26.50^{*}$ & 4 \\
\hline
\end{tabular}

Full sample $N=3,809$; sentinel $N=407$; nonsentinel $N=3,402$; rural $N=3,034$; urban $N=775$. SRMR $=$ standardized root mean square residual; $\mathrm{CFI}=$ comparative fit index; RMSEA = root mean square error of approximation.

a. FTP5, EDU1, EDU3

b. LOS3, LOS4, LOS6, FTP2

${ }^{*} p<.01$

indices for the series of CFA analyses conducted on the full sample). In Model 1, we examined model fit hypothesizing a single neglect factor. All items loaded significantly $(p<.05)$ on the factor identified. The fit indices, however, indicated that a single-factor model did not adequately fit the data.

In Model 2, we tested a four-factor model with emotional neglect, lack of supervision, failure to provide, and educational neglect items each loading on separate latent factors that were allowed to correlate. Correlations among the latent factors were high (average $r=.85$; see Table 3). Preliminary CFA models found that one item originally assigned to the Educational Neglect factor (EMO4) loaded more strongly on the Emotional Neglect factor, so we included it in all subsequent analyses as an indicator of emotional neglect. Respondents perhaps perceive this item ("A child is doing poorly in school and the parent fails to come to parent teacher conferences") as more indicative of neglect of the emotional than the educational needs of the child. In Model 2, all items loaded significantly $(p<.05)$ on their hypothesized factor. Fit indices suggested that the solution with four correlated factors was an appropriate fit to the data, and the chi-square 
Table 3. Standardized and Unstandardized Factor Loadings $(4+1$ Model $)$ and Latent Factor Correlations (From Four-Factor Model) for Full Sample

\begin{tabular}{|c|c|c|c|c|c|}
\hline Item & $\begin{array}{c}\text { Emotional } \\
\text { Neglect } \\
\text { (EMO) }\end{array}$ & $\begin{array}{l}\text { Lack of } \\
\text { Supervision } \\
\text { (LOS) }\end{array}$ & $\begin{array}{c}\text { Failure to } \\
\text { Provide } \\
\text { (FTP) }\end{array}$ & $\begin{array}{c}\text { Educational } \\
\text { Neglect } \\
\text { (EDU) }\end{array}$ & $\begin{array}{l}\text { Overall } \\
\text { Neglect } \\
\text { 2nd Order }\end{array}$ \\
\hline EMO1 & $.76(1.00)$ & & & & \\
\hline EMO2 & $.70(1.01)$ & & & & \\
\hline EMO3 & $.70(.96)$ & & & & \\
\hline EMO4 & $.75(1.00)$ & & & & \\
\hline LOS1 & & $.66(1.00)$ & & & \\
\hline LOS2 & & $.70(1.06)$ & & & \\
\hline LOS3 & & $.65(1.02)$ & & & \\
\hline LOS4 & & $.69(1.01)$ & & & \\
\hline LOS5 & & $.64(1.06)$ & & & \\
\hline LOS6 & & $.61(.91)$ & & & \\
\hline FTP1 & & & $.66(1.00)$ & & \\
\hline FTP2 & & & $.74(.81)$ & & \\
\hline FTP3 & & & $.70(1.02)$ & & \\
\hline FTP4 & & & $.71(1.04)$ & & \\
\hline FTP5 & & & $.58(.72)$ & & \\
\hline FTP6 & & & $.70(.81)$ & & \\
\hline EDU1 & & & & $.93(1.00)$ & \\
\hline EDU2 & & & & $.78(.96)$ & \\
\hline EDU3 & & & & $.78(1.11)$ & \\
\hline Emotional Neglect & & & & & $.93(.83)$ \\
\hline Lack of Supervision & .87 & & & & $.88(.72)$ \\
\hline Failure to Provide & .94 & .85 & & & $.98(.92)$ \\
\hline Educational Neglect & ct .83 & .79 & .84 & & $.86(.71)$ \\
\hline
\end{tabular}

Bold text indicates latent factor correlations from four-factor model (Model 2).

test indicated substantial and significant improvement over the fit of the single-factor model, $\Delta \chi^{2}(7)=1,901.11, p<.01$. Although the items appear to fit well to a model represented by four latent factors, a further hypothesis that can be tested is whether these four latent factors load on a single second-order latent factor representing an overall neglect standard.

In Model 3, we tested for the relative fit of such a second-order $(4+1)$ factor model, in which each of the four neglect subscales also loaded on a single higher order factor of overall neglect. This model estimates two fewer parameters than the model with four correlated factors and is therefore more parsimonious. The fit indices for Models 2 and 3 were very similar, with a slightly better RMSEA (.039) for the $4+1$ model. Comparison of the chi-square fit of Models 2 and 3 , 
however, did find a significant difference between the two, $\Delta \chi^{2}(2)=$ $10.57, p<.01$, indicating that allowing the four factors to be correlated fit slightly better than a model that assumed that a single second-order factor accounted for the correlations among the four factors. However, this chi-square difference was relatively small, and the $4+1$ model showed an improved RMSEA; thus, we believe the more parsimonious $4+1$ model is the preferred choice (see Table 3 for factor loadings of this model). What is clear is that both Models 2 and 3 represent an improvement over the single-factor model.

\section{Multiple Group Analyses}

Having determined that the $4+1$ model provided the most parsimonious structure and maintained a good fit to the combined sample data, we tested a series of models comparing the fit of this $4+1$ structure for sentinels and nonsentinels and for residents of rural and urban communities. We compared models in which all structural loadings were constrained to be equal between the groups to models where these loadings were allowed to vary freely. Chi-square tests and the fit indices for the free and constrained models and the values of the modification indices were used to identify items that accounted for differences between the models.

Sentinels versus nonsentinels. In Model 4 (see Table 2), we fit the $4+$ 1 model to sentinels and nonsentinels treated as two groups. In this first model, we constrained the item loadings on the four subfactors ( $\lambda$ coefficients) to be equal in both groups. In Model 5 , the loadings for all items were unconstrained, allowing them to vary across sentinel group status. For both Models 4 and 5, the fit statistics indicated an adequate fit to the data, with a small improvement in the SRMR index for Model 5. Examination of the chi-square difference test showed a significant reduction in chi-square gained by allowing all lambda coefficients to vary for sentinels and nonsentinels, $\Delta \chi^{2}(15)=27.22, p<$ .05, suggesting that some of the item loadings may differ for sentinels and nonsentinels.

Further examination of modification indices from Model 5 indicated that the source of most of the lack of fit was variation in the loadings of only three of the items. In Model 6, we constrained all lambda coefficients except for those of the three items, which we allowed to be 
estimated freely in both groups. Fit statistics for Model 6 indicated an adequate fit, and the chi-square difference test indicated this model produced a significant reduction in chi-square compared to Model 4, $\Delta \chi^{2}(3)=18.41, p<.01$ (see Table 4 for means and factor loadings of these three items that were allowed to vary for sentinels and nonsentinels). Comparing Models 5 and 6, the chi-square difference test was not significant, $\Delta \chi^{2}(12)=8.81, n s$, indicating that no further significant reduction in chi-square could be obtained by permitting the model to free up the loadings across the two groups for the remaining 16 items. Because fit indexes were so similar for the three models, and freeing some of the loadings between groups had little substantive effect on model fit, the more parsimonious Model 4 is preferred. This suggests that the structure of measurement in the CNCNS is quite similar across sentinels and nonsentinels. The three items that vary for sentinels and nonsentinels still had strong and statistically significant loadings on their respective factors in each group but varied

Table 4. Community Norms of Child Neglect Scale Items Varying Across Groups

\begin{tabular}{|c|c|c|c|c|c|c|}
\hline & \multirow[b]{2}{*}{ NS } & \multirow[b]{2}{*}{ Sent } & \multicolumn{2}{|c|}{$\begin{array}{l}\text { Standardized } \\
\text { Factor Loading }\end{array}$} & \multicolumn{2}{|c|}{$\begin{array}{l}\text { Unstandardized } \\
\text { Factor Loading }\end{array}$} \\
\hline & & & NS & Sent & NS & Sent \\
\hline \multicolumn{7}{|l|}{ Items varying across sentinel group status } \\
\hline $\begin{array}{l}\text { An infant with no medical problems does } \\
\text { not gain weight for over } 4 \text { months. }\end{array}$ & 4.16 (1.18) & 4.26 (1.08) & 0.74 & 0.53 & 0.59 & 0.41 \\
\hline $\begin{array}{l}\text { A parent allows his or her child to miss } \\
25 \text { days of school without explanation. }\end{array}$ & $4.43(0.98)$ & $4.44(0.78)$ & 1.00 & 0.88 & 0.85 & 0.81 \\
\hline \multirow{2}{*}{$\begin{array}{l}\text { A parent excuses his or her child from } \\
\text { school for } 25 \text { days in a semester. }\end{array}$} & $4.14(1.16)$ & $4.13(1.04)$ & 1.09 & 1.16 & 0.78 & 0.79 \\
\hline & Rural & Urban & Rural & Urban & Rural & Urban \\
\hline \multicolumn{7}{|l|}{ Items varying across rural and urban residence } \\
\hline $\begin{array}{l}\text { A 5-year-old does not ride in a } \\
\text { car seat while the parent is driving. }\end{array}$ & $4.06(1.25)$ & $4.13(1.25)$ & 0.65 & 0.69 & 0.82 & 0.86 \\
\hline $\begin{array}{l}\text { Parents allow school-age children to ride in } \\
\text { back of an open pickup on the highway. }\end{array}$ & $4.22(1.22)$ & $4.43(1.06)$ & 0.70 & 0.68 & 0.85 & 0.72 \\
\hline $\begin{array}{l}\text { A parent keeps a loaded firearm in the } \\
\text { nightstand by his or her bed. }\end{array}$ & $4.34(1.23)$ & $4.52(1.03)$ & 0.62 & 0.61 & 0.77 & 0.63 \\
\hline $\begin{array}{l}\text { An 8-year-old sleeps on a dirty mattress } \\
\text { without sheets. }\end{array}$ & $4.38(1.03)$ & 4.25 (1.03) & 0.75 & 0.70 & 0.77 & 0.72 \\
\hline
\end{tabular}

Sentinel $n=407$; nonsentinel $n=3,402$; rural $n=3,034$; urban $n=775$.

Standard deviations are shown in parentheses.

NS = nonsentinel; Sent $=$ sentinel. 
somewhat in the strength of the loading. Given the nearly identical fit indices of these three models and the small differences in coefficients of sentinels and nonsentinels, we conclude that the fit is effectively the same in both groups.

Rural versus urban participants. Fit indices for two-group models comparing rural and urban participants are presented in Table 2. In Model 7 , we estimated the $4+1$ model with item loadings ( $\lambda$ coefficients) on the four subfactors constrained to be equal across groups. In Model 8 , loadings for all items were unconstrained, allowing them to vary across rural-urban groups. For both Models 7 and 8, fit statistics indicated an adequate fit to the data, with slight improvements in fit for Model 8. The chi-square difference test showed a significant reduction in chi-square gained by allowing all item loadings to vary for rural and urban groups, $\Delta \chi^{2}(15)=33.49, p<.05$, suggesting that some items on the CNCNS may demonstrate a different structure for rural and urban participants.

Further examination of modification indices from Model 7 indicated that allowing item factor loadings to vary on four items would produce a statistically significant reduction in the chi-square value. In Model 9, we constrained all lambda coefficients except for those corresponding to the four items that had produced the highest modification indices, which were estimated freely for rural and urban respondents. Fit statistics for Model 9 indicated an adequate fit to the data, and the chi-square difference test indicated that Model 9 produced a significant reduction in chi-square relative to Model 7 , $\Delta \chi^{2}(4)=26.50, p<.05$ (see Table 4 for means and factor loadings of the four items that varied among rural and urban participants). Comparing Models 8 and 9, the chi-square difference test was not significant, $\Delta \chi^{2}(11)=6.99, n s$, indicating that no further statistically significant reduction in chi-square would result from freeing up the loadings for any additional items. As with sentinel status group comparisons, only the strength of the factor loadings for these four items varied significantly across rural and urban groups. Because the fit indices were so similar for the three models, freeing some of the loadings between groups had little substantive effect, and the more parsimonious Model 7 is preferred. Results of this comparison of rural and urban residents, together with the above findings comparing 
sentinel and nonsentinel groups, suggest that the factor structure tapping the dimensionality of standards of neglect are quite stable across sentinel and residential status.

\section{Scale Analyses}

Scale composite scores were constructed from 19 items as the average score of the available items (see Table 5 for descriptive analyses conducted for Overall Neglect and for each of the subscales, for the full sample and within groups). The table also reports the alpha reliability for each scale by residence and sentinel status; total scale alpha exceeds .9 for all groups and, with one exception (the Lack of Supervision scale among sentinels), exceeds .8 for all subscales and groups.

Analysis of scale composite score distributions revealed that each of the subscales and the Overall Neglect scale exhibited skewness and kurtosis outside of acceptable ranges. Thus, we transformed the scale composites by computing the squared value for each variable. This step successfully brought distribution properties within acceptable ranges (skewness values ranged from -.91 to -.25; kurtosis values ranged from -.79 to .15) for use in further analyses.

We next conducted an ANOVA and MANOVA with the transformed scales to test for significant effects of residence and sentinel status (see Table 6). The ANOVA with the Overall Neglect scale showed no significant differences in mean scale scores between residence or

Table 5. Descriptive Statistics and Alpha Reliability for Community Norms of Child Neglect Scale Overall Scale and Subscales

\begin{tabular}{|c|c|c|c|c|c|c|c|c|c|c|c|c|c|c|c|}
\hline \multirow[b]{2}{*}{ Factor } & \multicolumn{3}{|c|}{ Full Sample } & \multicolumn{3}{|c|}{ Sentinel } & \multicolumn{3}{|c|}{ Nonsentinel } & \multicolumn{3}{|c|}{ Rural } & \multicolumn{3}{|c|}{ Urban } \\
\hline & $M$ & $(S D)$ & $\alpha$ & $M$ & $(S D)$ & $\alpha$ & $M$ & $(S D)$ & $\alpha$ & $M$ & $(S D)$ & $\alpha$ & $M$ & $(S D)$ & $\alpha$ \\
\hline $\begin{array}{l}\text { Emotional Neglect } \\
\text { subscale ( } 4 \text { items) }\end{array}$ & 3.78 & $(0.97)$ & .81 & 3.64 & $(0.93)$ & .80 & 3.80 & $(0.98)$ & .82 & 3.80 & $(0.97)$ & .81 & 3.70 & $(0.99)$ & .83 \\
\hline $\begin{array}{l}\text { Lack of Supervision } \\
\text { subscale (6 items) }\end{array}$ & 4.11 & $(0.90)$ & .82 & 4.16 & $(0.72)$ & .73 & 4.11 & $(0.92)$ & .83 & 4.10 & $(0.91)$ & .82 & 4.17 & $(0.87)$ & .83 \\
\hline $\begin{array}{l}\text { Failure to Provide } \\
\text { subscale ( } 6 \text { items) }\end{array}$ & 3.88 & $(0.92)$ & .84 & 3.83 & $(0.81)$ & .80 & 3.89 & $(0.93)$ & .84 & 3.90 & $(0.92)$ & .84 & 3.78 & $(0.93)$ & .85 \\
\hline $\begin{array}{l}\text { Educational Neglect } \\
\text { subscale ( } 3 \text { items) }\end{array}$ & 4.33 & $(0.91)$ & .85 & 4.33 & $(0.78)$ & .83 & 4.33 & $(0.92)$ & .85 & 4.35 & $(0.90)$ & .84 & 4.26 & $(0.93)$ & .86 \\
\hline $\begin{array}{l}\text { Overall Neglect } \\
\text { norms scale ( } 19 \text { items) }\end{array}$ & 4.00 & $(0.82)$ & .94 & 3.97 & $(0.68)$ & .91 & 4.01 & $(0.83)$ & .94 & 4.01 & $(0.82)$ & .93 & 3.96 & $(0.82)$ & .94 \\
\hline
\end{tabular}

Full sample $N=3,809$; sentinel $N=407$; nonsentinel $N=3,402$; rural $N=3,034$; urban $N=775$. Scale range is from 0 (not neglect) to 5 (very serious neglect). 
Table 6. ANOVA and MANOVA Tests of the Effect of Sentinel and Residence Status on the Community Norms of Child Neglect Scale

\begin{tabular}{|c|c|c|c|c|}
\hline Model and Source & $d f$ & MSE & $F$ & $\eta^{2}$ \\
\hline \multicolumn{5}{|l|}{ ANOVA Total Neglect scale } \\
\hline Residence (rural/urban) & 1 & .045 & 0.79 & .000 \\
\hline Sentinel (yes or no) & 1 & .005 & 0.09 & .000 \\
\hline Residence $\times$ Sentinel interaction & 1 & .003 & 0.06 & .000 \\
\hline Error & 3805 & .057 & & \\
\hline \multicolumn{5}{|l|}{ MANOVA Neglect subscales } \\
\hline \multicolumn{5}{|l|}{ Multivariate test } \\
\hline Residence (rural/urban) & 4 & & $6.87^{\star \star}$ & \\
\hline Sentinel (yes or no) & 4 & & $5.92^{\star *}$ & \\
\hline Residence $\times$ Sentinel interaction & 4 & & 0.44 & \\
\hline Error & 3802 & & & \\
\hline \multicolumn{5}{|l|}{ Univariate tests in MANOVA } \\
\hline \multicolumn{5}{|l|}{ Residence } \\
\hline Emotional Neglect & 1 & .293 & 3.45 & .001 \\
\hline Failure to Provide & 1 & .143 & 2.01 & .001 \\
\hline Lack of Supervision & 1 & .274 & 3.45 & .001 \\
\hline Educational Neglect & 1 & .286 & $3.99^{*}$ & .001 \\
\hline \multicolumn{5}{|l|}{ Sentinel } \\
\hline Emotional Neglect & 1 & .477 & $5.62^{*}$ & .001 \\
\hline Failure to Provide & 1 & .156 & 2.20 & .001 \\
\hline Lack of Supervision & 1 & .032 & 0.40 & .000 \\
\hline Educational Neglect & 1 & .055 & 0.76 & .000 \\
\hline \multicolumn{5}{|l|}{ Residence $\times$ Sentinel interaction } \\
\hline Emotional Neglect & 1 & .025 & 0.29 & .000 \\
\hline Failure to Provide & 1 & .004 & 0.06 & .000 \\
\hline Lack of Supervision & 1 & .001 & 0.14 & .000 \\
\hline Educational Neglect & 1 & .038 & 0.53 & .000 \\
\hline \multicolumn{5}{|l|}{ Error } \\
\hline Emotional Neglect & 3805 & .085 & & \\
\hline Failure to Provide & 3805 & .071 & & \\
\hline Lack of Supervision & 3805 & .079 & & \\
\hline Educational Neglect & 3805 & .072 & & \\
\hline
\end{tabular}

${ }^{*} p<.05 ;{ }^{* *} p<.01$

sentinel groups or in the interaction of residence and sentinel status. The MANOVA with four subscales found an overall significant effect in the multivariate tests for residence and sentinel status but no significant interaction. Further examination of the univariate tests found only two significant effects. The Emotional Neglect mean was 
significantly lower for sentinels compared to nonsentinels. Nonsentinels perceived the emotional neglect situations to be more serious than did sentinels. Rural residents rated educational neglect as being significantly more serious than did urban residents.

We next examined the correlations of the scales with basic demographic characteristics of the respondents (see Table 7). The correlations among the scales indicated that all of the subscale composites were positively and strongly interrelated, consistent with latent factor correlations and results of our CFA indicating a higher order overall neglect factor. We chose to examine characteristics available in the data set that have been found in previous research to relate to perceived severity of potentially neglectful behaviors. Age and gender of the respondent were positively correlated with each of the subscales and the overall scale, with older participants and women giving higher severity ratings. Respondents from larger households rated all the types of neglect as being less serious than did those from smaller households. The correlations also indicated that respondents whose total household income was greater gave lower seriousness ratings than did those whose total household income was less. Finally, number of years of education negatively correlated with each of the subtypes; participants who reported more years of education gave lower seriousness ratings than participants who had fewer years of education.

Table 7. Intercorrelations of Neglect Subscales and Correlations of Neglect Factors with Demographic Variables

\begin{tabular}{|c|c|c|c|c|c|}
\hline Variable & $\begin{array}{c}\text { Emotional } \\
\text { Neglect } \\
\text { (EMO) }\end{array}$ & $\begin{array}{c}\text { Lack of } \\
\text { Supervision } \\
\text { (LOS) }\end{array}$ & $\begin{array}{c}\text { Failure to } \\
\text { Provide } \\
\text { (FTP) }\end{array}$ & $\begin{array}{c}\text { Educational } \\
\text { Neglect } \\
\text { (EDU) }\end{array}$ & $\begin{array}{l}\text { Overall } \\
\text { Neglect }\end{array}$ \\
\hline LOS & $.62^{* *}$ & - & & & \\
\hline FTP & $.73^{* \star}$ & $.68^{* *}$ & - & & \\
\hline EDU & $.77^{\star *}$ & $.64^{* *}$ & $.71^{\star *}$ & - & \\
\hline Overall Neglect & $.86^{\star *}$ & $.87^{* \star}$ & $.91^{\star \star}$ & $.85^{\star *}$ & - \\
\hline Age of respondent & $.17^{\star \star}$ & $.18^{* \star}$ & $.13^{* *}$ & $.18^{\star *}$ & $.18^{\star \star}$ \\
\hline Gender of respondent $($ female $=1)$ & $.08^{* *}$ & $.20^{* *}$ & $.13^{* *}$ & $.12^{\star *}$ & $.16^{\star \star}$ \\
\hline \# in household & $-.12^{\star *}$ & $-.09 * *$ & $-.09 * *$ & $-.09 * *$ & $-.11^{\star \star}$ \\
\hline Total household income & $-.12^{\star *}$ & $-.09 *$ & $-.13^{* *}$ & $-.06^{\star \star}$ & $-.11^{\star *}$ \\
\hline Years of education & $-.19 * *$ & $-.14^{\star *}$ & $-.21^{\star *}$ & $-.14^{\star *}$ & $-.19 * *$ \\
\hline
\end{tabular}

$N=3,809$

${ }^{*} p<.05 ;{ }^{* *} p<.01$ 


\section{Discussion}

This study provides support for use of the newly developed CNCNS in research situations involving assessment of lay community members' perceptions of child neglect. We have demonstrated that the total scale is reliable and correlates modestly with individual characteristics that might be expected to relate to perceptions of child neglect. Moreover, using CFA, we found that four subtypes of neglect that have been conceptually identified in previous work (Barnett et al., 1993) correspond well with how responses to this set of items empirically cluster in this sample. Additional confirmation of the stability of scale structure comes from multigroup confirmatory factor models in which we replicate the four-factor structure in responses of both lay community members and of respondents who meet the NIS definition of a sentinel. Because a large proportion of our sample lived in rural communities, we also were able to compare the responses of rural and urban dwellers and found marked similarity in the structure of the neglect scale in these two diverse residential settings.

Items included on the CNCNS were intended to probe variability in whether community members identified scenarios as indicating child neglect and variability in severity ratings for the items. As indicated in the appendix, the proportion of respondents who stated that they did not perceive a given scenario as representing neglect was very low, ranging from $1.1 \%$ to $5.4 \%$ of the full sample rating an item as "not neglect." The same general patterns followed for sentinel and residence status subgroups. This was a higher and less variable percentage of respondents rating items as indicating neglect than expected, given the ambiguity and low severity of many of the items. Although there was some variability across items and between groups, none of the scenarios, including those that would likely fall below a legal threshold for neglect, had fewer than 94\% of all participants stating that the situation did indicate neglect. As discussed by Dubowitz et al. (2005), a categorical classification as neglect or not neglect may not be the most valuable distinction. Rather, individuals likely perceive the potential for harm in each of these scenarios, making degree of severity the more important measure. However, this raises important questions about community members' threshold for intervention in situations perceived as presenting potential harm. 


\section{Item-Level Group Differences}

Although the four-factor structure was clear in each of the four groups we examined and, in each group, the items had adequate and significant factor loadings, several items had loadings that differed significantly between groups, indicating that not all items were viewed equivalently across groups. For example, one item in which an infant failed to gain weight loaded less strongly on the Failure to Provide factor for sentinels than for nonsentinels. Perhaps sentinels view this situation as a more specific type of neglect, such as medical neglect. In addition, as this scenario uniquely involves an infant, it is also possible that sentinels are more sensitive to developmental level in assessing situations than are nonsentinels. Two educational neglect items also varied across sentinel group status; nonsentinels viewed unexcused absences, and sentinels viewed excused absences, as indicators of educational neglect. Perhaps for community members the lack of parental explanation for truancy is indicative of a parent's neglecting the child's education, whereas for sentinels parental provision of excuses for school absences indicates that parents are active participants in children's truancy.

For rural-urban group analyses, three of the four items that differed significantly in their factor loadings were lack of supervision scenarios. For example, two items (child has access to a loaded gun, and parents allow school-age children to ride in the back of an open truck on the highway) were rated as more serious by urban participants than by rural participants, but both items loaded more strongly on the lack of supervision factor for rural than for urban participants. We speculate that these situations may be largely outside of urban, but not rural, participants' experiences or observations, contributing to their higher seriousness ratings (i.e., "I don't do this, and I don't know anyone who does."), and likewise are also less a part of their conceptualization of what constitutes a failure to adequately supervise children. Although these differences are largely consistent with our understanding of social and contextual factors in these groups that may influence the way they define neglect and perceive the seriousness of certain behaviors, it should be noted that the similarities of the loadings, even for these items, are substantially greater than the differences. Moreover, comparisons of fit indices between models 
that allow these items to vary between groups with those from models that assume invariance show only extremely small differences in fit between the two approaches.

\section{CNCNS Subtypes}

Mean differences in the seriousness ratings of neglect subtypes on the CNCNS indicated that community participants differentiate subtypes of child neglect in terms of their seriousness. In the full sample, and in each of the subgroups, seriousness ratings varied from highest to lowest in the following order: educational neglect, physical neglectlack of supervision, physical neglect-failure to provide, and emotional neglect. This ranking contrasts somewhat with prior research; in earlier studies, emotional or psychological neglect has been rated by both community members and child welfare professionals as being more serious or harmful for children, relative to neglect of children's physical care (e.g., Dubowitz et al., 1998; Giovannoni \& Beccerra, 1979; Rose \& Meezan, 1995). Based on Barnett et al.'s (1993) operational definition, we believe that each of the items composing the Emotional Neglect scale is relevant to the construct of emotional neglect and each represents a specific aspect of their definition (e.g., emotional support and security, age-appropriate autonomy). The emotional neglect scenarios included on the CNCNS would be rated as low severity under Barnett et al.'s system and thus may be more moderate than scenarios included in other measures. As earlier noted, we eliminated a higher severity emotional neglect item that was originally included in this scale because it caused a reduction in alpha for the scale. Rather than focusing solely on one aspect of emotional neglect, as earlier studies have tended to do, future research, including future versions of this measure, might aim to include items representing different aspects of emotional neglect with a greater severity range. In addition, emotional neglect items on the CNCNS all involve school-age or early adolescent children; it is possible that community members perceive situations involving older children to be less serious than those involving younger children (Ards \& Harrell, 1993). In addition, we thank our anonymous reviewers for pointing out that item EMO4, which was originally included as an educational neglect item but unexpectedly loaded on the Emotional Neglect subscale, may have done so because it is a "double-barreled" item and because items EMO1 and 
EMO2 are both phrased to include the word school. Rephrasing these items in a future version of this measure may help to clarify the construct of emotional neglect. Because educational neglect has been included in few studies (but see Giovannoni \& Beccerra, 1979; Rose \& Meezan, 1996), it is difficult to discern why items on this factor were perceived as being more serious than items on other factors, and this issue should be explored in future research.

Neglect subtype was important for differentiating seriousness ratings for subgroups of participants. No group differences in mean seriousness ratings emerged on the Overall Neglect scale, but small group differences were present on neglect subscales. Prior research (e.g., Dubowitz et al., 1998; Rose, 1999) suggested that sentinels might have a higher threshold for neglect than nonsentinel community membersin other words, sentinels would give lower seriousness ratings. The present study found this to be true only for emotional neglect. This finding may be because of the broader definition of a sentinel we used in the present study, compared with child welfare professional samples (e.g., CPS intake and investigation workers) used in prior studies. Comparisons of rural and urban participants' mean perceptions of seriousness indicate that rural participants rated educational neglect as being more serious than did urban participants. The extent to which these differences are attributable to variations in the values, cultural norms, or lifestyles of rural and urban individuals should be explored in future research. Finally, the effect sizes for both of these statistically significant differences are very small, which suggests that these differences have little substantive importance.

Correlational analyses indicate that subscale ratings on the CNCNS modestly relate to demographic characteristics in the overall sample. Consistent with prior research (e.g., Portwood, 1998; Shor, 2000), including one study in a rural sample (Ringwalt \& Caye, 1989), respondent gender and education were significantly correlated with perceptions of seriousness of neglect. Unexpectedly, total household income related negatively to all neglect subscales; participants with higher household income viewed all types of neglect scenarios as less serious. This appears to be inconsistent with Dubowitz and colleagues' (1998) findings that urban, middle-income caregivers rated poor psychological care as more harmful to the child than did an urban, lowincome African American group. However, cultural or regional differences may also account for this discrepancy. Ringwalt and Caye (1989) 
found income to be unrelated to perceptions of maltreatment when controlling for race, age, education, and occupation type.

Participants with more people in the household provided lower seriousness ratings. Although Dubowitz and colleagues (1998) found that number of children in the respondents' household was unrelated to perceptions of neglect, Portwood (1998) reported that more experienced parents rated a number of vignettes (involving neglect and other types of maltreatment) as being less serious than did less experienced parents. Finally, in evaluating these associations, it is important to note that most studies examining neglect or maltreatment perceptions have done so in smaller, more specific samples (e.g., comparing low-income, urban African American mothers with child welfare workers; Rose, 1999). It is possible that in a broader community sample, albeit in one regional area, these associations are more accurately represented. In future research, it will be important to examine how combined effects of individual characteristics and group membership relate to individuals' perceptions of neglect. This may help to tease apart correlated characteristics associated with neglect perceptions (e.g., sentinels typically have completed more education and are more likely to be female than nonsentinels) and to account for more variance in understanding perceptions of neglect.

\section{Limitations}

Several limitations of this study should also be noted. First, our sample included very little racial or ethnic diversity, so our findings do not reflect differences that may exist across racial or ethnic groups (e.g., Dubowitz et al., 1998; Ringwalt \& Caye, 1989; Rose \& Meezan, 1996). Pending further research in more diverse samples or studies focused on specific racial or ethnic groups, findings from this study apply primarily to European Americans. Furthermore, we were not able to include participants in the most densely populated urban centers (MSAs of at least 1 million people) because they were not present in the state studied. Relatedly, this midwestern sample could be different from populations in other regions of the country. This scale should be tested in more diverse samples in future research, in very urban areas, and in other regions. Second, regarding possible limitations of the scale itself, although our initial goal was to include items that would allow variability in severity ratings, item means were still skewed, probably 
indicating positive response bias (see also Dubowitz et al., 1998). The addition of more ambiguous items, or inclusion of other dimensions of neglect (e.g., chronicity, intent), might enhance the ability of the scale to differentiate subtle variation in perceptions of what constitutes neglect. Third, although we did not intend the scale to comprehensively cover all possible domains of neglect, a possible limitation may be the lack of items tapping medical neglect or other dimensions of neglect linked to both legal definitions and children's basic needs. Earlier versions of the scale explored in the pilot study contained some items assessing medical neglect that we discarded from the version included on the larger survey because of their poor psychometric properties. A final limitation is that additional studies are needed to explore the convergent validity of the scales. Although we are aware of no "goldstandard" measure of perceptions of child neglect, it may be worthwhile to assess further the validity of this approach by examining correspondence of the CNCNS subscales to other related measures. For example, the Neglect Scale (Strauss et al., 1995) assesses self-reports of experienced emotional, cognitive, physical, and supervision neglect, and Dubowitz and colleagues' (1998) Adequacy of Care measure assesses perceptions of appropriate physical and psychological care.

\section{Conclusions and Implications}

Despite these limitations, this study had several key strengths. Namely, this study involved the rigorous testing of a new measure of perceptions of child neglect in a large sample that is diverse in terms of rural-urban ecology and socioeconomic and demographic characteristics other than race/ethnicity. More broadly, the measure presented in this study reflects both conceptual and empirical approaches to considering child neglect types, consistent with recommendations (e.g., Zuravin, 1999). Because the items and scales in this study are linked to both common state legal definitions (i.e., child welfare standards) and to children's basic needs, this measure is appropriate for use in research contexts. Although our specific goal was to develop a brief measure that would enable us to assess community norms of child neglect, the CNCNS could also be used to assess individual-level perceptions. In summary, the CNCNS is promising as a brief measure of perceptions of the seriousness of subtypes of neglect. Using this scale, we demonstrated that a broad community sample does distinguish among 
a set of child neglect subtypes in terms of their perceived seriousness and that this more differentiated view of neglect is in better alignment with community members' perceptions than is a broad, undifferentiated neglect factor. This measure should support researchers' capacities to assess differentiated community perceptions of child neglect norms and deserves further research and validation in future studies.

\section{References}

Amato, P. R. (1993). Urban-rural differences in helping friends and family members. Social Psychology Quarterly, 56, 249-262.

Ards, S., \& Harrell, A. (1993). Reporting of child maltreatment: A secondary analysis of the National Incidence surveys. Child Abuse \& Neglect, 17, 337-344.

Barnett, D., Manly, J. T., \& Cicchetti, D. (1993). Defining child maltreatment: The interface between policy and research. In D. Cicchetti \& S. L. Toth (Eds.), Child abuse, child development, and social policy (pp. 7-73). Norwood, NJ: Ablex.

Belsky, J. (1980). Child maltreatment: An ecological integration. American Psychologist, 35, 320-335.

Belsky, J. (1993). Etiology of child maltreatment: A developmental-ecological analysis. Psychological Bulletin, 114, 413-434.

Bensley, L., Ruggles, D., Simmons, K. W., Harris, C., Williams, K., Putvin, T., et al. (2004). General population norms about child abuse and neglect and associations with childhood experiences. Child Abuse \& Neglect, 28, 1321-1337.

Brown, D. L., \& Hirschl, T. A. (1995). Household poverty in rural and metropolitan-core areas of the United States. Rural Sociology, 6o, 44-66.

Coulton, C. J., Korbin, J. E., Su, M., \& Chow, J. (1995). Community level factors and child maltreatment rates. Child Development, 66, 1262-1276.

Craft J. L., \& Staudt, M. M. (1991). Reporting and founding of child neglect in urban and rural communities. Child Welfare, 70, 359-370.

Dubowitz, H., Klockner, A., Starr, R. H., Jr., \& Black, M. M. (1998). Community and professional definitions of child neglect. Child Maltreatment, 3, 235-243.

Dubowitz, H., Newton, R. R., Litrownik, A. J., Lewis, T., Briggs, E. C., Thompson, R., et al. (2005). Examination of a conceptual model of child neglect. Child Maltreatment, 10, 173-189.

Fischer, C. (1982). To dwell among friends. Chicago: University of Chicago Press.

Flax, J., Wagenfeld, M., Ivens, M., \& Weiss, R. (1979). Mental health in rural America. Rockville, MD: National Institute of Health.

Giovannoni, J. M., \& Beccerra, R. M. (1979). Defining child abuse. New York: Free Press.

Harrington, D., Zuravin, S., DePanfilis, D., Ting, L., \& Dubowitz, H. (2002). The Neglect Scale: Confirmatory factor analysis in a low-income sample. Child Maltreatment, 7, 359-368. 
Heller, P. L., Queseda, G. M., Harvey, D. L., \& Warner, L. G. (1981). Familism in rural and urban America: Critique and reconceptualization of a construct. Rural Sociology, 46, 446-464.

Hill, M. (1997). SPSS missing value analysis 7.5. Chicago: SPSS Inc.

Hong, G. K., \& Hong, L. K. (1991). Comparative perspectives on child abuse and neglect: Chinese versus Hispanics and Whites. Child Welfare, 70, 463-475.

Hu, L., \& Bentler, P. M. (1999). Cutoff criteria for fit indices in covariance structure analysis: Conventional criteria versus new alternatives. Structural Equation Modeling, 6, 1-55.

Lichter, D. T., \& Eggebeen, D. J. (1992). Child poverty and the changing rural family. Rural Sociology, 57, 151-172.

Manly, J., Cicchetti, D., \& Barnett, D. (1994). The impact of subtype, frequency, chronicity, and severity of child maltreatment on social competence and behavior problems. Development and Psychopathology, 6, 121-134.

Muthen, L. K., \& Muthen, B. O. (2004). Mplus: User's guide (3rd ed.). Los Angeles: Muthen \& Muthen.

Osgood, D. W., \& Chambers, J. (2000). Social disorganization outside the metropolis: An analysis of rural violence. Criminology, 38, 81-115.

Portwood, S. G. (1998). The impact of individual's characteristics and experiences on their definitions of child maltreatment. Child Abuse \& Neglect, $22,437-452$.

Price, J. H., Islam, R., Gruhler, J., Dove, L., Knowles, J., \& Stults, G. (2001). Public perceptions of child abuse and neglect in a Midwestern urban community. Journal of Community Health, 26, 271-284.

Ringwalt, C., \& Caye, J. (1989). The effect of demographic factors on perceptions of child neglect. Children and Youth Services Review, 11, 133-144.

Roscoe, B. (1990). Defining child maltreatment: Ratings of parental behaviors. Adolescence, 25, 517-528.

Rose, S. J. (1999). Reaching consensus on child neglect: African American mothers and child welfare workers. Children and Youth Services Review, 21, 463-479.

Rose, S. J., \& Meezan, W. (1995). Child neglect: A study of the perceptions of mothers and child welfare workers. Children and Youth Services Review, 17, 471-486.

Rose, S. J., \& Meezan, W. (1996). Variations in perceptions of child neglect. Child Welfare, 75, 139-160.

Sedlak, A., \& Broadhurst, D. (1996). Third National Incidence Study of Child Abuse and Neglect: Final report (NIS-3). Washington, DC: Government Printing Office.

Shor, R. (2000). Child maltreatment: Differences in perceptions between parents in low income and middle income neighborhoods. British Journal of Social Work, 30, 165-178.

Steblay, N. M. (1987). Helping behavior in rural and urban environments: A metaanalysis. Psychological Bulletin, 102, 346-356. 
Strauss, M. A., Kinard, E. M., \& Williams, L. M. (1995). The Multidimensional Neglectful Behavior Scale, Form A: Adolescent and adult-recall version. Durham: University of New Hampshire. Available from http://pubpages.unh. edu/ mas2/

Trocmé, N. (1996). Development and preliminary evaluation of the Ontario Child Neglect Index. Child Maltreatment, 1, 145-155.

U.S. Department of Health and Human Services, Administration on Children, Youth and Families. (2006). Child maltreatment 2004. Washington, DC: Government Printing Office.

Wagenfeld, M., \& Wagenfeld, J. (1981). Values, culture, and the delivery of mental health services in rural areas. In M. Wagenfeld (Ed.), New directions for mental health services (Vol. 9, pp. 1-12). San Francisco: Jossey-Bass.

Wilkinson, K. P. (1991). The community in rural America. Westport, CT: Greenwood.

Zuravin, S. J. (1999). Child neglect: A review of definitions and measurement research. In H. Dubowitz (Ed.), Neglected children (pp. 24-46). Thousand Oaks, CA: Sage.

Zuravin, S. J., \& Taylor, R. (1987). The ecology of child maltreatment: Identifying and characterizing high-risk neighborhoods. Child Welfare, 66, 497-506.

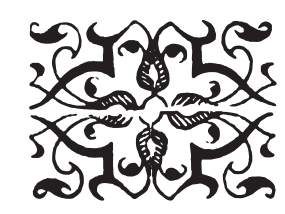




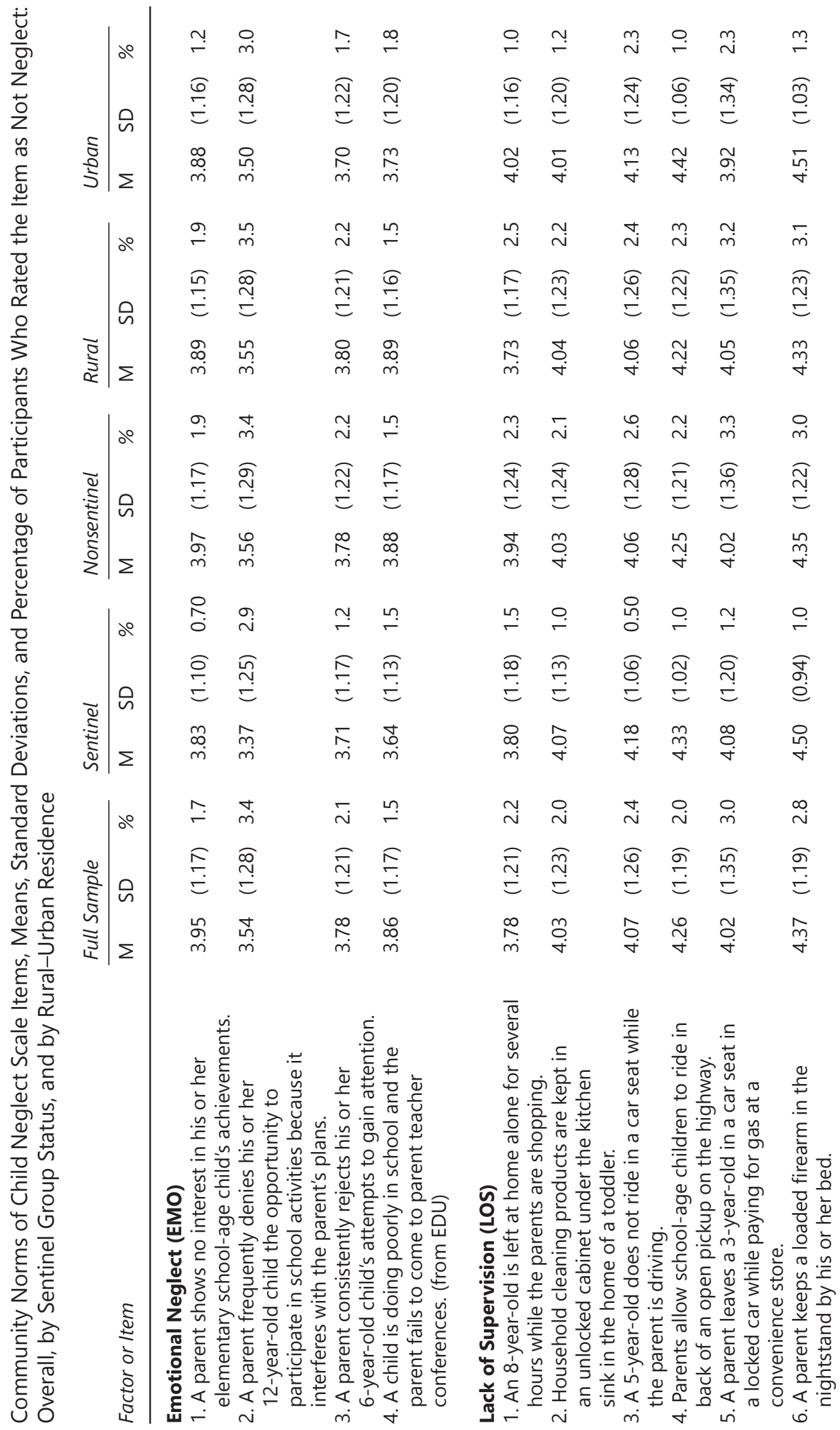




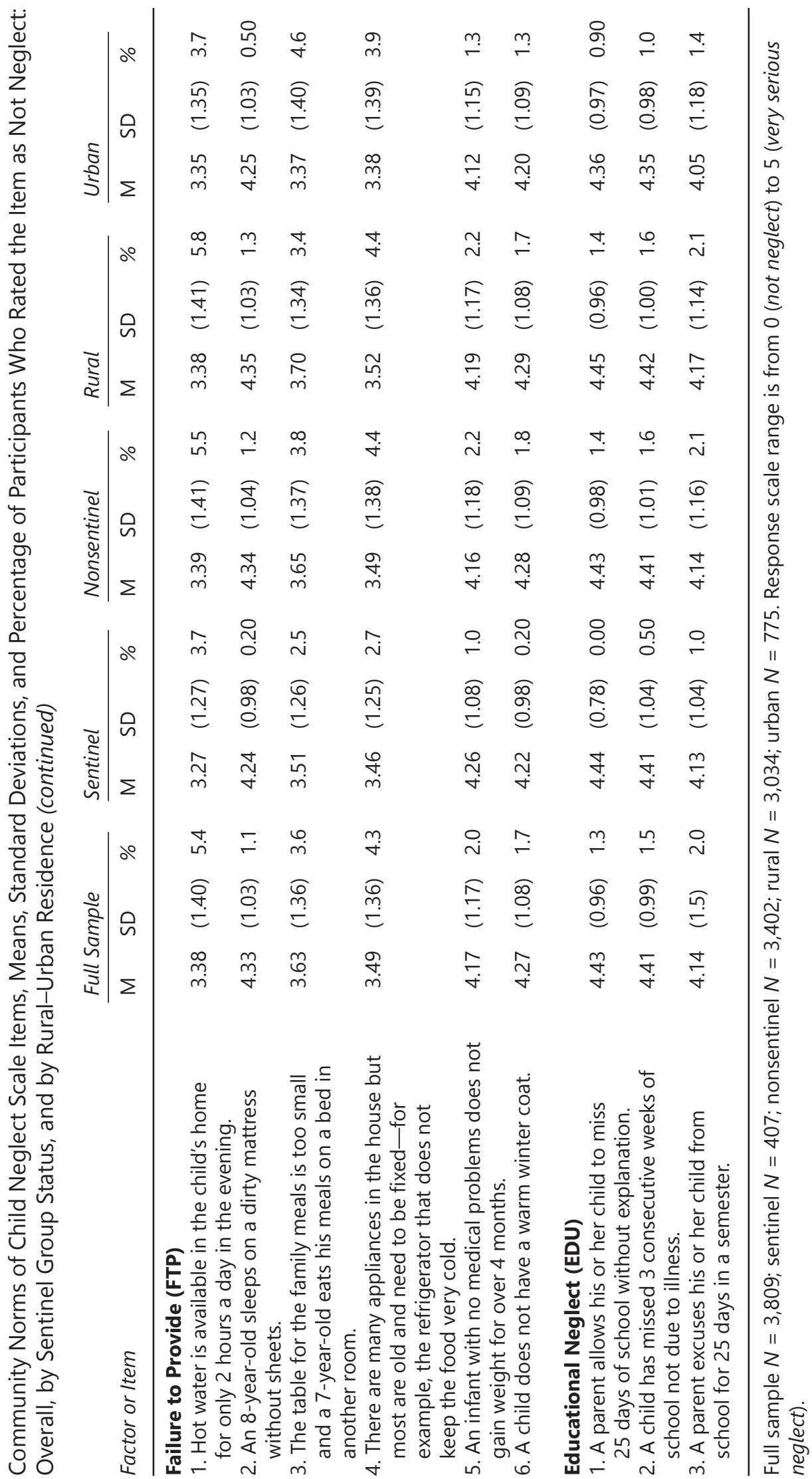




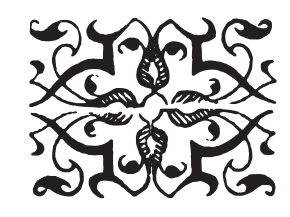

Rebecca Goodvin is a doctoral candidate in the Department of Psychology at the University of Nebraska-Lincoln and is a research assistant at the Center on Children, Families, and the Law at the University of Nebraska-Lincoln. Her work there has encompassed a wide range of research areas related to contexts and institutions affecting children and families.

David R. Johnson is professor of sociology, human development and family studies, and demography at the Pennsylvania State University and director of the Survey Research Center. He received his PhD in sociology from Vanderbilt University. His research has focused on the family over the life course, rural and urban mental health, quantitative methods, and hormones and behavior and has appeared in more than 80 articles and book chapters.

Sam A. Hardy is a postdoctoral research fellow in the Department of Psychology at the University of Virginia. He received his PhD in developmental psychology from the University of Nebraska-Lincoln. His research primarily focuses on examining personality factors that motivate moral action, the development of moral motivation, and individual and contextual influences on these processes.

Michelle I. Graef is research associate professor of psychology at the Center on Children, Families, and the Law at the University of Nebraska-Lincoln. Her research and consultation projects focus on a variety of child welfare human resource management issues, such as job analysis; staff recruitment, selection, and retention strategies; training program evaluation; performance evaluation systems; design of training for new CPS supervisors; and quality assurance. Current projects include research on the determinants of CPS worker job performance and turnover and a study of CPS intake decision making in child neglect cases.

Jeff M. Chambers is research manager at the Center on Children, Families, and the Law at the University of Nebraska-Lincoln. His research interests include rural community structure and social organization, juvenile delinquency, child maltreatment rate variation, city and county human service planning, and residential energy efficiency improvement in low-income homes. In addition, he serves as the chair for the Nebraska Management Information System and is the program director of the Lincoln Community Services Management Information System. 